\title{
Maternal Mortality with SARS-COV-2 during its 4th Wave in Pakistan: The Vaccine Paradox and Pregnancy
}

\author{
Javaria Aslam¹, Momina Masroor ${ }^{1}$, Qurat-ul-Ain Mehmood ${ }^{1}$, Munazza Arshad², Salma Jabeen ${ }^{3}$ and Muhammad \\ Azam Mushtaq ${ }^{2}$ \\ ${ }^{1}$ Department of Medicine, Sir Sadiq Abbasi Hospital, Qauid-e-Azam Medical College, Bahawalpur, Pakistan \\ ${ }^{2}$ Department of Pulmonology, Quaid-e-Azam Medical College, Bahawalpur, Pakistan \\ ${ }^{3}$ Department of Obstetrics and Gynaecology, Sir Sadiq Abbasi Hospital, Quaid-e-Azam Medical College, Bahawalpur, Pakistan
}

\begin{abstract}
The goal of this study was to investigate the maternal death rate among admitted pregnant patients with SARS-COV-2 during its $4^{\text {th }}$ wave in Pakistan. It was a cross-sectional analytical study, carried on pregnant patients admitted due to COVID-19, in Sadiq Abbasi Hospital from $15^{\text {th }}$ August to $15^{\text {th }}$ September, 2021. Thirty-three PCR confirmed and HRCT suggestive patients were included with mean age of $28 \pm 4.5$ years and mean gestational age of $28.5 \pm 6$ weeks. Twenty-seven (81\%) were non-vaccinated, 22 (66\%) were admitted with severe disease, $13(39.4 \%)$ and 11 (33.3\%) were on non-invasive and invasive ventilator support, respectively. Only nine (27\%) patients could continue their pregnancy. Fifteen (45\%) patients had severe oligohydramnios. Twenty-two (66.7\%) patients were died, all were unvaccinated. Regression analysis for maternal mortality predicted by severity and vaccination status was significant with $\mathrm{R}^{2}=.68, \mathrm{~F}(1,31)=66.6, \mathrm{p}<.001 \mathrm{Cl}(-.69,-.42)$ and $\mathrm{R}^{2}=.44, \mathrm{~F}(1,31)=24.8$, $\mathrm{p}<.001 \mathrm{Cl}(-1.14,-.48)$, respectively. There was substantial mortality in the admitted and non-vaccinated pregnant patients with COVID-19.
\end{abstract}

Key Words: Pregnancy, Vaccination, Severe COVID, Maternal outcome.

How to cite this article: Aslam J, Masroor M, Mehmood QUA, Arshad M, Jabeen S, Mushtaq MA. Maternal Mortality with SARS-COV-2 during its 4th Wave in Pakistan: The Vaccine Paradox and Pregnancy. J Coll Physicians Surg Pak 2022; 32(01):119-121.

Since, the world was stricken by COVID-19 pandemic, caused by SARS-COV-2, it had wreaked havoc in every corner of the world. Clinical presentation varies from mild to critical illness. Risk factors had been identified for developing severe disease such as old age, diabetes and obesity. Pregnancy is found to be a risk factor for any viral or bacterial infection because of shift in cellular immunity to humoral immunity. ${ }^{1}$ COVID-19 has bi-directional impact on pregnancy. On one hand severe and inappropriate immunogenic inflammatory response (IL-1, IL-6, TNF) in severe COVID-19, whichcancauseadverse pregnancy outcomee.g.abortion, preterm birth and pre-eclampsia and IUD in more severe cases; on the other hand, mechanical effect of gravid uterus on diaphragm compromises the functional residual lung volume and adding to severity of ARDS. In the first year of pandemic of COVID-19, maternal mortality was not high as there were few case reports on it. ${ }^{2}$ With arrival of variants of concern (VOC), like delta variant B.1.167.2, maternal mortality showed alarming figures. ${ }^{3}$

Correspondence to: Dr. Javaria Aslam, Department of Medicine, Sir Sadiq Abbasi Hospital, Qauid-e-Azam

Medical College, Bahawalpur, Pakistan

E-mail: javaslam50@gmail.com

Received: October 04, 2021; Revised: November 02, 2021; Accepted: November 09, 2021

DOI: https://doi.org/10.29271/jcpsp.2022.01.119
Seeing pregnant and lactating women omitted from COVID vaccine trials, there is indeed a vacuum of scientific evidence to vaccinate this high risk population. Despite the fact that maternal deaths have been documented, the frequency with which this dreadful consequence happens is undetermined. So, we have designed a study at COVID dedicated hospital to see maternal and fetal outcomes in pregnant ladies admitted to hospital with COVID-19.

This observational study was conducted among pregnant patients admitted to High Dependency Unit (HDU) and Intensive Care Unit (ICU) of Sir Sadiq Abbasi Hospital, Bahawalpur from $15^{\text {th }}$ August to $15^{\text {th }}$ September, 2021. Patient's data were noted from electronic record and hospital charts. After approval from the Ethical Review Board, (No. 1129, dated: July $21^{\text {st }}$ 2021), 33 pregnant patients with PCR confirmed and HRCT suggestive COVID-19 infection were included in the study. Patients were divided into mild, moderate and severe cases, according to symptoms, oxygen saturation and HRCT scoring. Body mass index (BMI) of patients before getting pregnant were noted from antenatal record and divided into normal weight $\left(18.5-24.9 \mathrm{Kg} / \mathrm{m}^{2}\right)$, overweight $\left(25-29.9 \mathrm{Kg} / \mathrm{m}^{2}\right)$ and obese $\left(>30 \mathrm{Kg} / \mathrm{m}^{2}\right)$. Mode of oxygen delivery, obstetric intervention, antenatal complication developed during COVID illness, and vaccination status were also noted. Outcomes were measured in terms of maternal deaths or clinical improve- 
ments; and fetal outcomes in terms of intra-uterine deaths on admission to hospital or during hospital stay, alive births and early neonatal deaths.

Data was analysed through SPSS version 20. Frequencies and percentages of categorical variables were calculated. Pearson correlation, bivariate and multiple regression analysis were applied to find out correlation and predictability of outcome by independent variables, keeping $p$-value $<0.05$ as statistically significant.

Thirty-three pregnant women with age range of 19 to 38 years, mean age of $28 \pm 4.6$ years were included in the study. Their mean gestational age was $28.5 \pm 6$ weeks and mean BMI was $25.5 \pm 3.1 \mathrm{Kg} / \mathrm{m}^{2}$. Frequencies of categorical variables are shown in Tablel.

Table I: Frequencies of categorical variables.

\begin{tabular}{|c|c|c|}
\hline Variables & $n$ & $\%$ \\
\hline \multicolumn{3}{|l|}{ Age } \\
\hline $18-30$ years & 25 & 75.8 \\
\hline More than 30 years & 8 & 24.2 \\
\hline \multicolumn{3}{|l|}{ Gestational age } \\
\hline First trimester & 1 & 3 \\
\hline Second trimester & 6 & 18.2 \\
\hline Third trimester & 26 & 78.8 \\
\hline \multicolumn{3}{|l|}{ Obstetric history } \\
\hline Primary gravid & 10 & 30.3 \\
\hline Multiparous & 23 & 69.7 \\
\hline \multicolumn{3}{|l|}{ Body mass index } \\
\hline Normal weight & 15 & 45.5 \\
\hline Overweight & 17 & 51.5 \\
\hline Obese & 1 & 3 \\
\hline \multicolumn{3}{|l|}{ Vaccination status } \\
\hline Vaccinated & 6 & 18.2 \\
\hline Non vaccinated & 27 & 81.8 \\
\hline \multicolumn{3}{|l|}{ Severity of disease } \\
\hline Mild illness & 4 & 12.1 \\
\hline Moderate & 7 & 21.2 \\
\hline Severe to critical & 22 & 66.7 \\
\hline \multicolumn{3}{|l|}{ Mode of oxygen delivery } \\
\hline No oxygen support & 5 & 15.2 \\
\hline Non invasive ventilator & 13 & 39.4 \\
\hline Invasive ventilation & 11 & 33.3 \\
\hline Via face mask & 4 & 12.1 \\
\hline \multicolumn{3}{|l|}{ Antenatal complications } \\
\hline No complication & 10 & 30.3 \\
\hline Oligohydramnios & 15 & 45.5 \\
\hline $\mathrm{PIH}$ & 6 & 18.2 \\
\hline IUD & 2 & 6.1 \\
\hline \multicolumn{3}{|l|}{ Obstetric Intervention } \\
\hline No intervention & 19 & 57.6 \\
\hline Spontaneous delivery & 2 & 6 \\
\hline C Section & 10 & 30.3 \\
\hline Obstetric hysterectomy PPH & 2 & 6.1 \\
\hline
\end{tabular}

Twenty-two $(66.7 \%)$ pregnant patients were died, all were unvaccinated and only 11 (33.3\%) patients were discharged, among them six (54.5\%) were fully vaccinated. Nine (27.3\%) patients continued their pregnancy. Five (15.2\%) delivered alive baby with good Apgar score during hospital stay, three $(9.1 \%)$ babies were died in early neonatal period, and 16 (48.5\%) were died in utero. Six vaccinated patients developed mild to moderate disease, clinically improved and continued their pregnancy. Ten (30.3\%) patients underwent C Sections and two $(20 \%)$ out of those improved after Cesarean section; whereas, eight $(80 \%)$ patients could not improve after Cesarean section and were died. Pearson correlation shows strong negative relationship among vaccination status and maternal outcome, severity of disease, antenatal complications, and fetal outcome $(r=.67, p<.001),(r=.816, p<.001)$, $(r=.49, p=.004)$ and $(r=.47, p=.006)$, respectively.

The $R^{2}$ for regression equation for predicting maternal outcome from vaccination status was .44 , with $F(1,31)=24.8, p<.001$. Cl $[-1.15,-.481]$.

The findings support a high death rate of 66 percent in hospitalised pregnant patients. Forty- five percent patients developed severe oligohydramnios as an ante-natal complication due to severe disease and $73.3 \%$ out of those had IUD later during hospital stay, while $6 \%$ patients had IUD on admission to hospital. These results are consistent with high rates of ante-natal complications, and bad fetal outcome in patients who need admission to hospital with COVID-19. Majority studies published in initial one year of pandemic of COVID-19 showed pregnancy to be a low risk factor for severe disease; and those who developed critical illness, had other risk factors of obesity, increase maternal age, and diabetes mellitus. ${ }^{4}$ In this study, $75 \%$ patients were between the age group of 18-30 years, and only $3 \%$ had obese range BMI, which shows maternal age and weight to have an insignificant role for mortality. Study also does not support termination of pregnancy to relieve the pressure of gravid uterus on diaphragm in order to increase residual lung volume. As $80 \%$ patients, who underwent $C$ section, could not survive. ${ }^{5}$ According to CDC guidelines updated on $11^{\text {th }}$ August 2021, vaccination for COVID-19 is recommended for pregnant and lactating mothers as they are more likely to get severe infection; and may become seriously ill with COVID 19. Seeing the good maternal and fetal outcome among vaccinated patients, it is need of the hour to start an effective nationwide awareness programmes for encouragement of vaccination in pregnant ladies; and myths regarding getting antenatal complications, congenital anomalies, and infertility should be omitted from the society. Post-marketing studies of several vaccines in pregnant and lactating mothers have shown their safety and immunogenicity. ${ }^{6}$

In summary, symptomatic and severe COVID-19 with pregnancy was associated with alarming rate of maternal mortality, ante-natal complications and poor fetal outcomes. There was good outcome in patients who were vaccinated before getting pregnant. Thus, vaccination is the only way to reduce mortality in pregnant patients and get rid of preventable tragedy. Moreover, it will be easiest to state then to be done, as a lot of rumors about vaccination are already circulating in the society. So, a mass awareness programme for both obstetricians and patients is needed to prevent further loss.

\section{ETHICALAPPROVAL:}

The study was approved by Institutional Ethical Review Board of Qauid-e-Azam Medical College, Bahawalpur, No. 1129, 
dated: July $21^{\text {st. }} 2021$. Approval was taken prior to initiation of research work.

\section{PATIENTS' CONSENT:}

Informed consents had been taken from all patients; and in some casesfrom gaurdians to publish the data for this study.

\section{CONFLICT OF INTEREST:}

The authors declared no conflict of interest.

\section{AUTHORS' CONTRIBUTION:}

JA: Conceptualisation, study design, formal analysis, interpretation and drafting of the work.

MM, QM: Data acquisition and analysis.

MA: Conceptualisation and study design.

SJ, MAM: Final approval of the work.

\section{REFERENCES}

1. Alberca RW, Pereira NZ, Oliveira LMDS, Gozzi-Silva SC, Sato MN. Pregnancy, viral infection, and COVID-19. Front Immunol 2020; 11:1672. doi: 10.3389/fimmu.2020.01672.
2. Pettirosso E, Giles M, Cole S, Rees M. COVID-19 and pregnancy: A review of clinical characteristics, obstetric outcomes and vertical transmission. Aust New Zeal J Obstet Gynaecol 2020; 60(5):640-59. doi: 10.1111/ajo.13204.

3. Lapinsky SE, Adhikari NKJ. COVID-19, variants of concern and pregnancy outcome. Obstet Med 2021; 14(2):65-6. doi: 10.1177/1753495X211028499.

4. Hessami K, Homayoon N, Hashemi A, Vafaei H, Kasraeian M, Asadi N. COVID-19 and maternal, fetal and neonatal mortality: A systematic review. J Matern Neonatal Med 2020; 2020:1-6. doi: 10.1080/14767058.2020.1806817.

5. Kolkova Z, Bjurström MF, Länsberg JK, Svedas E, Hamer MA, Hansson SR, et al. Obstetric and intensive-care strategies in a high-risk pregnancy with critical respiratory failure due to COVID-19: A case report. Case Rep Women's Health 2020; 27:e00240. doi: 10.1016/j.crwh.2020.e00240.

6. Collier ARY, McMahan K, Yu J, Tostanoski LH, Aguayo R, Ansel $\mathrm{J}$, et al. Immunogenicity of COVID-19 mRNA vaccines in pregnant and lactating women. JAMA - J Am Med Assoc 2021; 325(23):2370-80. doi: 10.1001/jama.2021.7563. 